This item was submitted to Loughborough's Research Repository by the author.

Items in Figshare are protected by copyright, with all rights reserved, unless otherwise indicated.

\title{
European Union support for sanitation in sub-Saharan Africa: aid flows and effectiveness
}

PLEASE CITE THE PUBLISHED VERSION

http://dx.doi.org/10.2166/washdev.2012.106

PUBLISHER

(C) IWA Publishing

VERSION

AM (Accepted Manuscript)

LICENCE

CC BY-NC-ND 4.0

\section{REPOSITORY RECORD}

Cotton, Andrew P., B. Valfrey-Visser, P. van Maanen, and Rebecca E. Scott. 2019. "European Union Support for Sanitation in Sub-saharan Africa: Aid Flows and Effectiveness". figshare.

https://hdl.handle.net/2134/11491. 
This item was submitted to Loughborough's Institutional Repository (https://dspace.lboro.ac.uk/) by the author and is made available under the following Creative Commons Licence conditions.

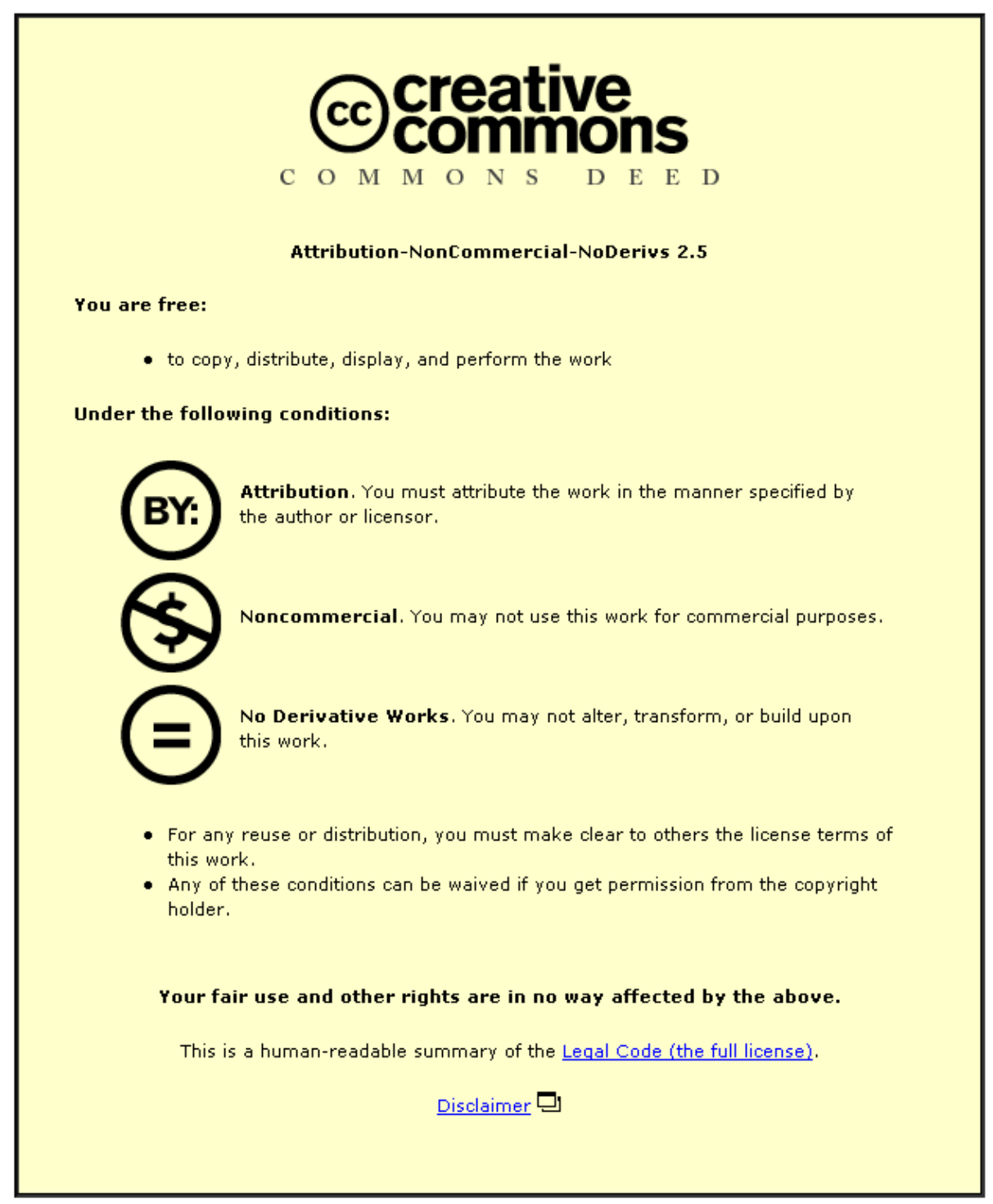

For the full text of this licence, please go to: http://creativecommons.org/licenses/by-nc-nd/2.5/ 


\title{
European Union Support for Sanitation in Sub-Saharan Africa: Aid Flows and Effectiveness
}

A Cotton (corresponding Author), WEDC, Loughborough University, Loughborough LE11 3TU UK, a.p.cotton@lboro.ac.uk

B Valfrey-Visser, Hydroconseil, 198, Chemin d'Avignon 84470, Chateauneuf de Gadagne, France

P van Maanen, Hydroconseil, 198, Chemin d'Avignon 84470, Chateauneuf de Gadagne, France

R Scott, WEDC, Loughborough University, Loughborough LE11 3TU UK

\begin{abstract}
Within sub-Saharan Africa, 569 million people, amounting to $69 \%$ of the population, do not use improved sanitation. This study presents an overview of European Union donor support to sanitation in sub-Saharan Africa and proposes a method for investigating the effectiveness of national sanitation programmes through linking aid flows to sanitation outcomes in terms of trends in open defecation; this can be used to locate the relative performance of different countries. The work addresses key concerns of the African Ministers' Council on Water and the European donors around the need to increase support to sanitation. Results show that European Union donors are the major source of external finance for sanitation in sub-Saharan Africa. Case studies from Mozambique, Uganda and Burkina Faso show that the majority of national planned expenditure on sanitation comes from donor sources, with EU donors being the substantive contributors. National policies on subsidy for sanitation and expenditure allocations vary extremely widely and do not necessarily align with sanitation outcomes. European Union Member States’ donor policies on sanitation are consistent and well-aligned with those of the African Union; this is a major achievement for Europe and Africa.
\end{abstract}


Inadequate national monitoring of sanitation expenditure remains a constraint to determining programme effectiveness.

Key words | aid effectiveness, donor support, financing, monitoring, policy, sanitation

\section{ABBREVIATIONS AND ORGANISATIONS}

AMCOW

African Ministers’ Council on Water

CRS

Creditor Reporting System

CSO Country Sector Overview

DAC Development Assistance Committee

EU European Union

GLAAS Global Annual Assessment of Drinking Water and Sanitation

MDGs Millennium Development Goals

OD $\quad$ Open defecation

OECD Organisation for Economic Co-operation and Development

ODA Official Development Assistance

WHO World Health Organisation

WSS Water supply and sanitation

\section{INTRODUCTION}

The United Nations Development Summit in 2000 agreed a set of time-bound and measurable goals for international development efforts. Donor agencies that support the water and sanitation sector have been strongly driven by the resulting Millennium Development Goals (MDGs) and their associated targets. With 2015 rapidly approaching, globally 2.6 billion (2.6 $\mathrm{x} 10^{9}$ ) people do not use improved sanitation, making access to sanitation the most off-track of all the MDG targets. Within sub-Saharan Africa, 569 million people, amounting to 69\% of 
the population, do not use improved sanitation (WHO/UNICEF 2010). Furthermore, the Global Annual Assessment of Sanitation and Drinking Water report (GLAAS 2010) presents a bleak picture of the financial resources flowing to the sector with 35 out of the 37 countries surveyed reporting that financial flows were insufficient to achieve the MDG target for sanitation and 32 having insufficient finance to reach the drinking water target. In 2008, development aid for sanitation and drinking water amounted to US\$7.4 x $10^{9}$ (GLAAS 2010) whereas global cost estimates to reach the MDG target vary enormously from US $\$ 6.7 \times 10^{9}$ to US\$75 $\times 10^{9}$ per year depending on the assumptions made (WELL 2005a).

Important regional initiatives have focused attention on the problems of sanitation in Africa. The eThekwini Declaration and Action Plan (2008), signed by Ministers from 32 countries, pledges a number of commitments, including policy development and improved financial resources. The European Union (EU) subsequently voiced its support through the development of the joint Africa-EU Statement on Sanitation (EU Water Initiative Africa Working Group 2008a).

The purpose of this study is to obtain an overview of the status of European Union support for sanitation in sub-Saharan Africa in terms of policy alignment and financial support through Official Development Assistance (ODA). The study proposes an approach for reviewing the effectiveness of national sanitation programmes through linking financial flows with sanitation outcomes, as measured by trends in the practice of open defecation, in three case study countries. The European Union, comprising the European Commission and EU Member States represents one of the largest groups of donors supporting water and sanitation in subSaharan Africa; this study addresses key concerns of both the African Ministers' Council on Water (AMCOW) and European donors to accelerate the progress of national sanitation plans 
and attain the MDG target on sanitation. It is anticipated that the findings of this work will have the potential for use by recipient governments and donors to discuss Official Development Assistance and to argue for greater priority for sanitation within the international architecture. The paper is based on original research commissioned by the Africa Working Group of the EU Water Initiative (Cotton et al. 2010).

\section{METHOD}

This research uses a mix of documentary and quantitative analysis to address the three components of the work as follows.

\section{Donor policy review}

This component identifies the extent to which the EU gives due recognition to investments in sanitation as part of Official Development Cooperation. Evidence is drawn from documentation publicly available in October 2010, including policy papers, strategy documents and official reports on activities in the sector. The comparative analysis addresses: the policy framework; levels of service; outputs and targets; financial considerations; and institutional roles and responsibilities (WEDC 2005) in order to assess the extent to which aspects of donor policy "can serve to set priorities and provide the basis for translating needs into action, creating conditions in which sanitation can be improved” (Ellege et al. 2002).

\section{Official development assistance data}

The Organisation for Economic Co-operation and Development (OECD) Development Assistance Committee (DAC) Creditor Reporting System (CRS) collects information on aid flows at activity level from the bilateral and multilateral donors who are members of the DAC (including all EU Member States and the European Commission). ODA for drinking water 
supply and sanitation is reported as being for either 'large' (Code 14020) or 'basic' (Code 14030) systems. Basic sanitation indicates latrines and on-site disposal systems; large systems cover sewerage and wastewater treatment (OECD Development Co-operation Directorate 2010). It is reasonable to assume that support for basic water and sanitation systems is a reasonable proxy for targeting poorer groups. The database (OECD Development Cooperation Directorate n.d.) is searchable by donor, recipient country, region, sub-region and aid-type for a particular reference year.

Prior to 2011, the CRS data do not disaggregate between water and sanitation. This study uses additional primary data made available to the authors from the preparation of the GLAAS report (GLAAS 2010). These data, from eight EU bilateral donors (Finland, France, Denmark, Germany, Netherlands, Portugal, Sweden and United Kingdom, hereafter referred to as the EU donor group), estimate the distribution of their ODA between water supply and sanitation for the reference year of 2008. These distributions were applied to the reported ODA in order to estimate the total ODA specifically for sanitation, including both grant and loan aid for sub-Saharan Africa. This study uses disbursements, rather than commitments, as the measure of ODA as this better describes aid flows from the recipients' point of view. For EU donors, disbursements closely follow commitments (EU Water Initiative Africa Working Group 2008b). The reported data for sanitation do not distinguish between investments in sanitation hardware and hygiene promotion software. Whilst the data set is somewhat limited, it does comprise the latest data that disaggregates ODA for water supply from sanitation and is sufficient to demonstrate the extent of EU financial support. Previous work (EU Water Initiative Africa Working Group 2008b) also noted the difficulties encountered in trying to disaggregate ODA for sanitation. 


\section{Country case study data}

Burkina Faso, Mozambique and Uganda were selected for the country case studies as these fitted with the wider body of work on aid effectiveness commissioned by the EU Water Initiative’s Africa Working Group (EU Water Initiative Africa Working Group 2008b; Zipper \& Hofbauer 2010). The overall criteria for choice were: to give sub-regional balance within Africa; to ensure that countries were in receipt of significant ODA from EU Member States; and countries for which national level resource allocation data for sanitation were available at the time this research was carried out during late 2010. In addition to the available data on ODA, further financial data were obtained from the country sector overview studies (AMCOW 2011) which identify governments’ planned expenditure on sanitation disaggregated into internal and external components; these refer to the respective contributions to the total from the government's own financial resources and those of its donors. The detailed primary data on which the country analyses are based are reported separately (Cotton et al. 2010).

\section{RESULTS AND DISCUSSION}

\section{EU donor policy on sanitation}

The political statement from the first AfricaSan Conference (2002) stresses the importance of policy development and raising the profile of sanitation:

"Develop and strengthen the clear policies and institutional frameworks needed to improve sanitation and hygiene...Raise the profile of sanitation and hygiene in all political and developmental processes. These include:...regional bodies such as the African Union and the African Ministerial Conference on Water” 
Since 2002, many African countries (including the case study countries) and European Member States have developed either specific sanitation policies, or overarching policies that make clear reference to sanitation. The policies of 14 EU Member States who contribute significantly to supporting sanitation in Africa have been analysed. Box 1 compares and contrasts the key attributes and highlights common concerns.

\section{Box 1. Attributes of EU Member States' Sanitation Policies}

\section{Policy context}

France and Germany have publicly available, separate strategy documents that focus on sanitation. The UK policy has a section dedicated to sanitation needs, opportunities and actions - based on a more comprehensive background paper that is no longer in the public domain.

Some Member States have aspects of sanitation policy and strategy combined into the broader approach of Integrated Water Resources Management (Austria, Denmark, France, Luxembourg and Sweden) or within the context of sustainable development (Spain). Others make specific reference to sanitation within the context of hygiene promotion (Denmark), support to health (Finland), sustainable urban environments (France), transition from relief to development and humanitarian assistance (Ireland and Luxembourg), contributing through ecological sanitation to environmental protection and agricultural production (Sweden).

\section{Approaches}

The majority of established donors identify the significance of moving towards greater harmonization and coordination, to increase aid effectiveness and coherence. Some donors make specific mention of generic approaches, but the general sense is one of a need to align with national (recipient) processes. 
Where donors identify how they cooperate with country governments, it is not given in specific terms. It is based more on elements of programme implementation than in relation to the allocation and tracking of financial assistance.

\section{Monitoring}

All major donors make reference to the importance of monitoring. Its purpose is given a number of interpretations, including: as a means to monitor the impact of development cooperation (Austria, France, Germany and Italy); to identify areas for change and effectively allocate further resources (Finland and Ireland); to improve efficiency and accountability and as the basis for future planning (Germany); to measure progress against commitments (Austria, Greece, Spain, UK); and to improve alignment and coordination of assistance (Luxembourg and UK). This has important implications with respect to monitoring at the country level.

\section{Funding allocation}

Commitments to funding sanitation are identified by France and Germany (of which about $50 \%$ and $40 \%$ respectively are reported as being allocated to sanitation only) and to the sector as a whole by the UK. Germany and Italy give figures for how much is contributed through multi-lateral organizations. Portugal and the UK both state that "almost half of their ODA" is via multi-lateral development cooperation.

Mechanisms for effective allocation of funds in-country include: decentralized financial mechanisms (Austria); cross subsidies and tariff structures that enable pro-poor services (at least to minimum levels of service) for urban services and community-managed systems 
based on cost-recovery for rural services (Denmark); subsidies focused on promotion and awareness creation, rather than for construction (Sweden).

EU Member States’ donor policies on sanitation are consistent and well-aligned with those of the African Union, with consistent policy messages that sit within recognized political frameworks that encompass both EU Member States and African States, through adoption by the African Union of the principles outlined in the Africa-EU Statement on Sanitation (2009). This provides a sound basis and agreed principles for individual states (both European and African) to mutually support the development and implementation of national plans and represents a major achievement for Europe and Africa in the period following the first AfricaSan conference in 2002.

\section{EU financing for sanitation in Africa}

Analysis of the data from both the OECD Creditor Reporting System and the GLAAS for the eight EU donors (the donor group), for whom disaggregated data are available for water supply and sanitation, demonstrates both the significance of aid flows to the region and the extent to which that aid is targeted.

- 35\% (US\$156 million) of their ODA for water supply and sanitation in sub-Saharan Africa goes to sanitation.

- $54 \%$ (US\$83 million) of their ODA for all sanitation in sub-Saharan Africa goes to basic sanitation.

- $15 \%$ of their ODA for all water supply and sanitation for the whole of Africa goes to basic sanitation in sub-Saharan Africa.

Earlier work concluded that EU donors directed a similar proportion (30\%) of their ODA for the water sector specifically to sanitation during 2006-2008 (EU Water Initiative Africa 
Working Group 2008b). For basic water and sanitation systems in sub-Saharan Africa, the ODA from these eight donors accounts for $66 \%$ of the total ODA from the EU for basic systems. All EU donors taken together provide 59\% of the total ODA for water supply and sanitation in sub-Saharan Africa. Similarly, the EU's contribution to basic water supply and sanitation is even greater at $70 \%$ of the total ODA. Whilst it is not possible to fully disaggregate sanitation ODA for all EU Member States, alignment of these findings makes it clear that EU donors are a major source of external finance for sanitation, as well as for basic water supply and sanitation services as a whole, in sub-Saharan Africa. Taking support for basic water and sanitation as a proxy for targeting poorer groups, this also indicates that EU support is generally well-aligned with its poverty-focused policy commitments.

\section{Financing national sanitation plans in the case study countries}

Detailed budget analysis for financial flows to sanitation in each of the three case study countries is shown in Table 1; this indicates the planned expenditure based on the population requiring access, according to agreed national rural and urban coverage targets.

Table 1.Sources of funding and allocations for governments' planned expenditure on sanitation.

\begin{tabular}{|c|c|c|c|c|}
\hline $\begin{array}{l}\text { All } \\
\text { Sanitation }\end{array}$ & $\begin{array}{l}\text { Pop'n } \\
\text { requiring } \\
\text { access } \\
\text { '000/year }\end{array}$ & $\begin{array}{c}\text { Internal } \\
\text { allocations } \\
10^{6} \mathrm{US} \$ \text { / year }\end{array}$ & $\begin{array}{c}\text { External allocations } \\
10^{6} \mathrm{US} \$ / \text { year }\end{array}$ & $\%$ external \\
\hline Mozambique & 906 & 5 & 31 & $86 \%$ \\
\hline Uganda & 2271 & 0.4 & 13 & $97 \%$ \\
\hline $\begin{array}{l}\text { Burkina } \\
\text { Faso }\end{array}$ & 1238 & 2 & 15 & $94 \%$ \\
\hline $\begin{array}{l}\text { Rural } \\
\text { Sanitation }\end{array}$ & $\begin{array}{l}\text { Pop'n } \\
\text { requiring } \\
\text { access } \\
\text { '000/year }\end{array}$ & $\begin{array}{c}\text { Internal } \\
\text { allocations } \\
\text { US\$/person/year }\end{array}$ & $\begin{array}{c}\text { External allocations } \\
\text { US\$/person/year }\end{array}$ & $\begin{array}{c}\text { Total } \\
\text { US\$/person/year }\end{array}$ \\
\hline $\begin{array}{l}\text { Mozambique } \\
\text { Uganda } \\
\text { Burkina } \\
\text { Faso }\end{array}$ & $\begin{array}{c}353 \\
1730 \\
956\end{array}$ & $\begin{array}{c}2.8 \\
0 \\
1.0\end{array}$ & $\begin{array}{l}5.6 \\
1.7 \\
8.4\end{array}$ & $\begin{array}{l}8.4 \\
1.7 \\
9.4\end{array}$ \\
\hline
\end{tabular}




\begin{tabular}{l|cccc}
$\begin{array}{l}\text { Urban } \\
\text { Sanitation }\end{array}$ & $\begin{array}{c}\text { Pop’n } \\
\text { requiring } \\
\text { access } \\
\text { '000/year }\end{array}$ & $\begin{array}{c}\text { Internal } \\
\text { allocations } \\
\text { US\$/person/year }\end{array}$ & $\begin{array}{c}\text { External allocations } \\
\text { US\$/person/year }\end{array}$ & $\begin{array}{c}\text { Total } \\
\text { US\$/person/year }\end{array}$ \\
$\begin{array}{l}\text { Mozambique } \\
\text { Uganda }\end{array}$ & 553 & 7.2 & & \\
Burkina & 541 & 0.7 & 52.4 & 59.6 \\
Faso & 282 & 3.5 & 18.5 & 28.7 \\
& & & &
\end{tabular}

The majority of national planned expenditure on sanitation (86\%-97\%) comes from external donor sources, with EU donors being substantive contributors. It is not possible to disaggregate EU donor ODA for sanitation for each specific country. However, by inference, ODA from the EU accounts for a high proportion of national expenditure on sanitation given that the EU provides 70\%-79\% of all ODA for basic water supply and sanitation as shown in Figure 1.

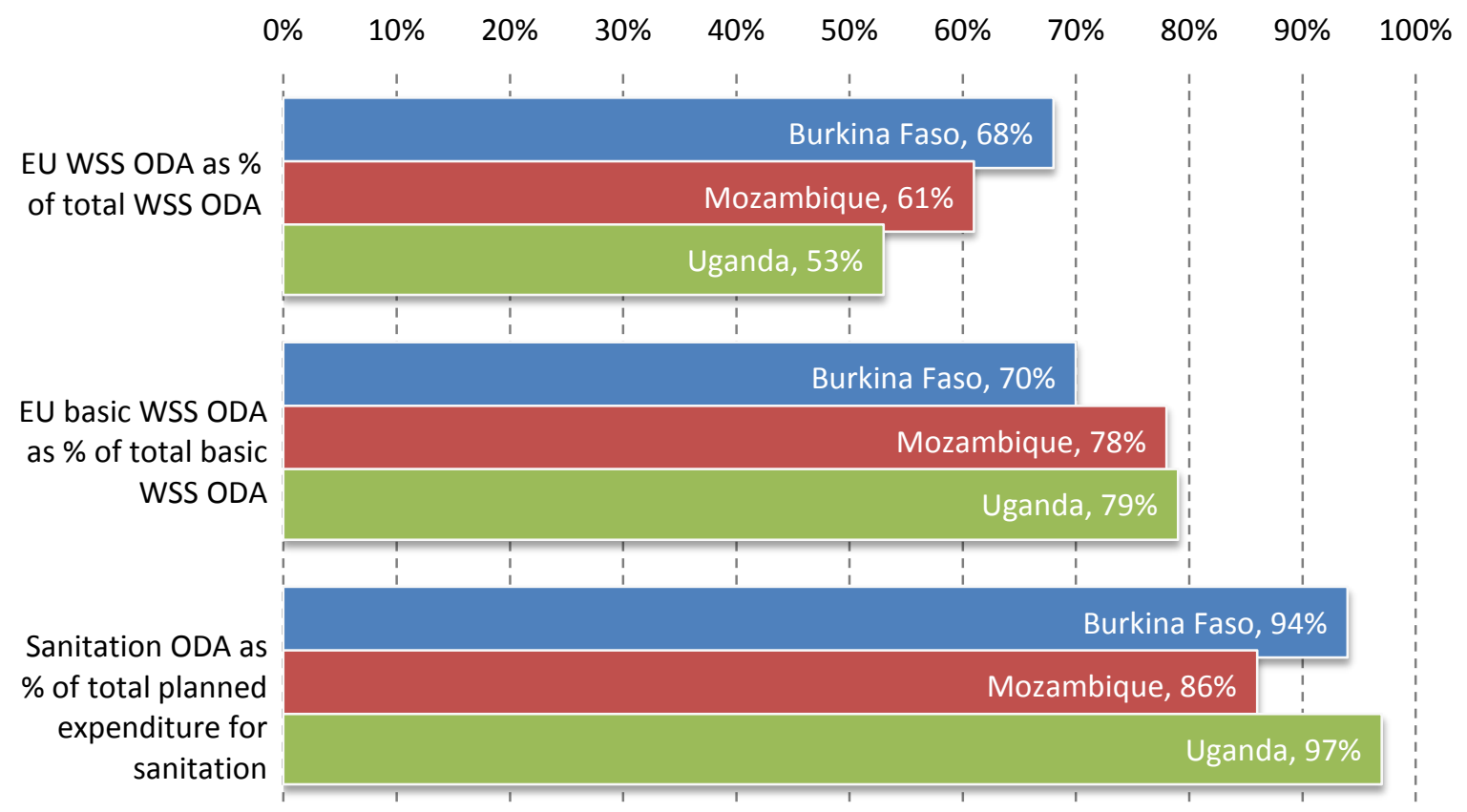

Figure 1. EU contributions to water supply and sanitation (WSS) and planned expenditure in the case study countries. 


\section{Disparities between financing for urban and rural sanitation in the case study countries}

Table 1 reveals remarkably wide variations in both the total planned expenditure and the relative allocations between rural and urban sanitation. Uganda and Burkina Faso both need to cover 3 times as many rural people as urban, whereas Mozambique needs to cover 1.5 times as many urban as rural. However, the ratio of urban to rural investment based on the number of people having no current access to adequate sanitation is 11 for Uganda, 3 for Burkina Faso and 7 for Mozambique.

An earlier study of resource allocation to water supply (WELL 2005b) for Ethiopia, Uganda and Mozambique drew similar conclusions regarding urban/rural investment allocations in water supply for the period 2002-2004. The corresponding ratios of urban to rural investment based on the number of people having no access to safe water were 11 for Uganda and Ethiopia, and 14 for Mozambique.

Considering that a much higher proportion of people in urban areas already have access to water supply and sanitation, the urban-rural differences are more significant. It is to be expected that per capita costs of provision are likely to be greater in urban areas where there is a greater need for infrastructure and service networks. However, the differences in resource allocations do not appear to relate directly to the numbers of un-served either for water supply (in 2005) or sanitation (in 2008).

For sanitation, there appear to be two contributing issues.

- The wide range of per capita unit costs used to develop expenditure plans; and 
- the allocation of subsidies, as measured by the proportion that households are expected to pay (Table 2).

Table 2. Subsidies to sanitation

$\begin{array}{ccc}\text { Urban } & \text { Urban } & \text { Rural } \\ \text { subsidy } & \begin{array}{c}\text { Rural capital costs } \\ \text { of latrine, } \\ \text { US\$person. }\end{array} & \begin{array}{c}\text { Subsidy } \\ \text { unit capital costs } \\ \text { of latrine, } \\ \text { US\$/person. }\end{array}\end{array}$

\begin{tabular}{|l|cccc|}
\hline Mozambique & $62 \%$ & 86 & $60 \%$ & 39 \\
Uganda & $48 \%$ & 34 & $6 \%$ & 12 \\
Burkina Faso & $94 \%$ & 45 & $100 \%$ & 17
\end{tabular}

Note that the measure used to indicate subsidy is the ratio of governments' planned expenditure / (governments planned expenditure + total expected household contributions for capital expenditure)

Assigning realistic unit costs for planning both urban and rural sanitation programmes is clearly problematic and data are limited. In Burkina Faso the capital cost of latrines is reported to vary from US\$54-US\$109 for rural, and US\$105-US\$177 for urban (Klutsé et al. 2010), although it is not possible to compare these data with Table 2 as the units of analysis are different. The rural-urban resourcing split is a difficult planning decision that has important implications in relation to national programming approaches and subsidy policy.

\section{IMPLICATIONS}

\section{Aligning financial flows and subsidies with sanitation outcomes}

The levels of subsidy vary widely from zero to $100 \%$, with generally higher subsidies allocated for urban sanitation. These are based on the national sanitation policies operational in 2008 and apply to households involved in government-sponsored sanitation programmes. However, it is difficult to generalise as, in reality, a significant proportion of the population are likely to be outside the reach of government programmes and projects exist which do not 
conform to the norm. Subsidies are under discussion in each of the countries; for example, in Burkina Faso the government has recently (2010) started to differentiate between different levels of subsidy.

The extent of open defecation (OD) practice in rural areas is a useful sanitation outcome measure that is now regularly monitored internationally (WHO/UNICEF 2010). Over the period 2000 to 2008, all three countries show a decrease in the percentage of the rural population practising open defecation. However, due to population increase, the absolute numbers of people practising open defecation have fallen substantially only in Uganda. Figure 2 juxtaposes the number of people practising OD against unit costs and levels of subsidy. Uganda, with very low subsidy and low unit capital cost allocations contrasts starkly with Burkina Faso which shows the opposite trend; Mozambique lies somewhere in between.

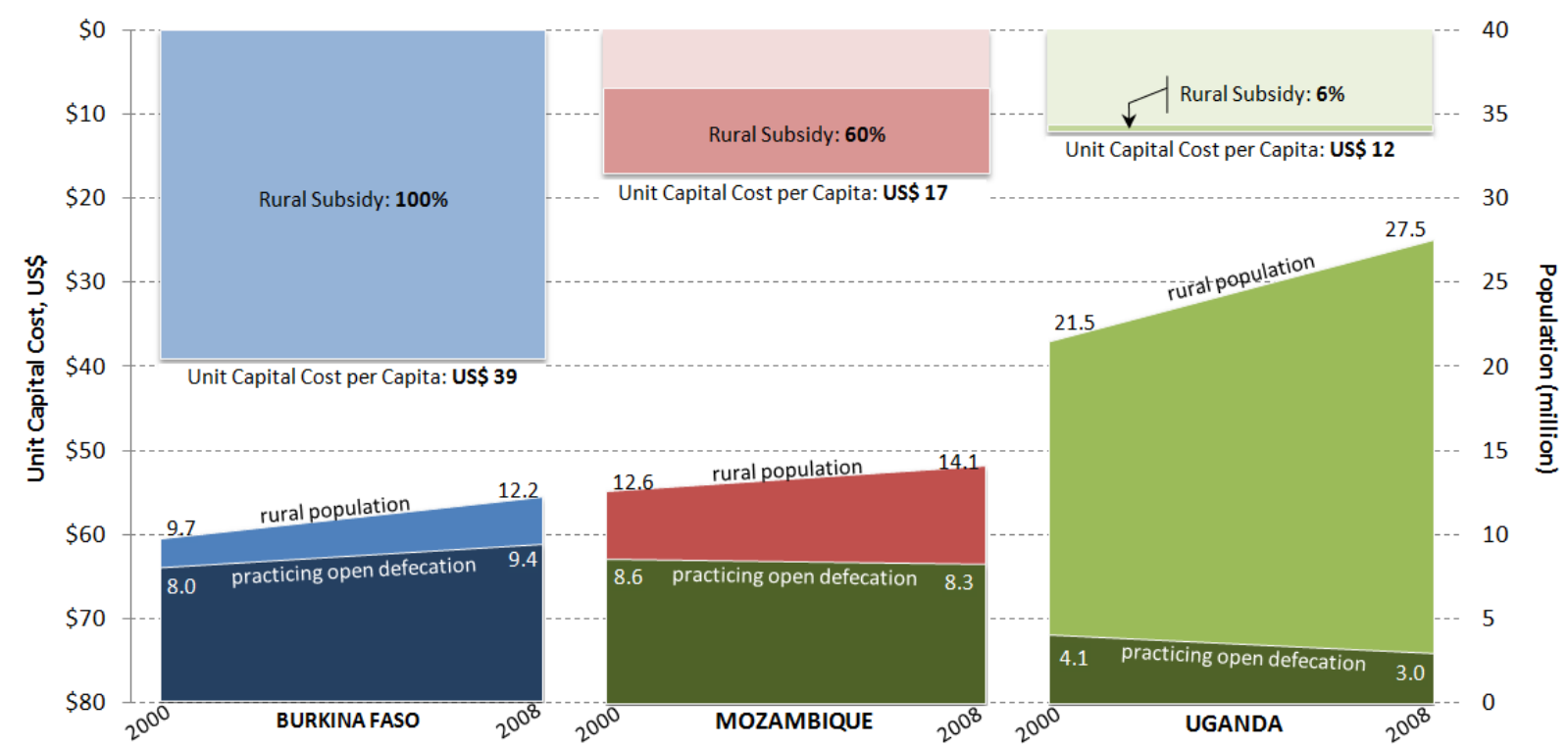

Figure 2. Trends in the rural population practising open defecation in relation to subsidy and unit capital cost of latrines 
The trend is similar when the open defecation values are compared with the external component (that is, ODA) per capita unserved of governments' planned expenditure on rural sanitation. Figure 3 shows a best estimate of the relative contribution of EU ODA (per capita unserved) to rural sanitation in the three countries alongside the changes in open defecation. The number of people practising open defecation in Uganda has declined; ODA per capita is low. Burkina Faso receives the highest ODA per capita of the three study countries and the population practising open defecation has increased.

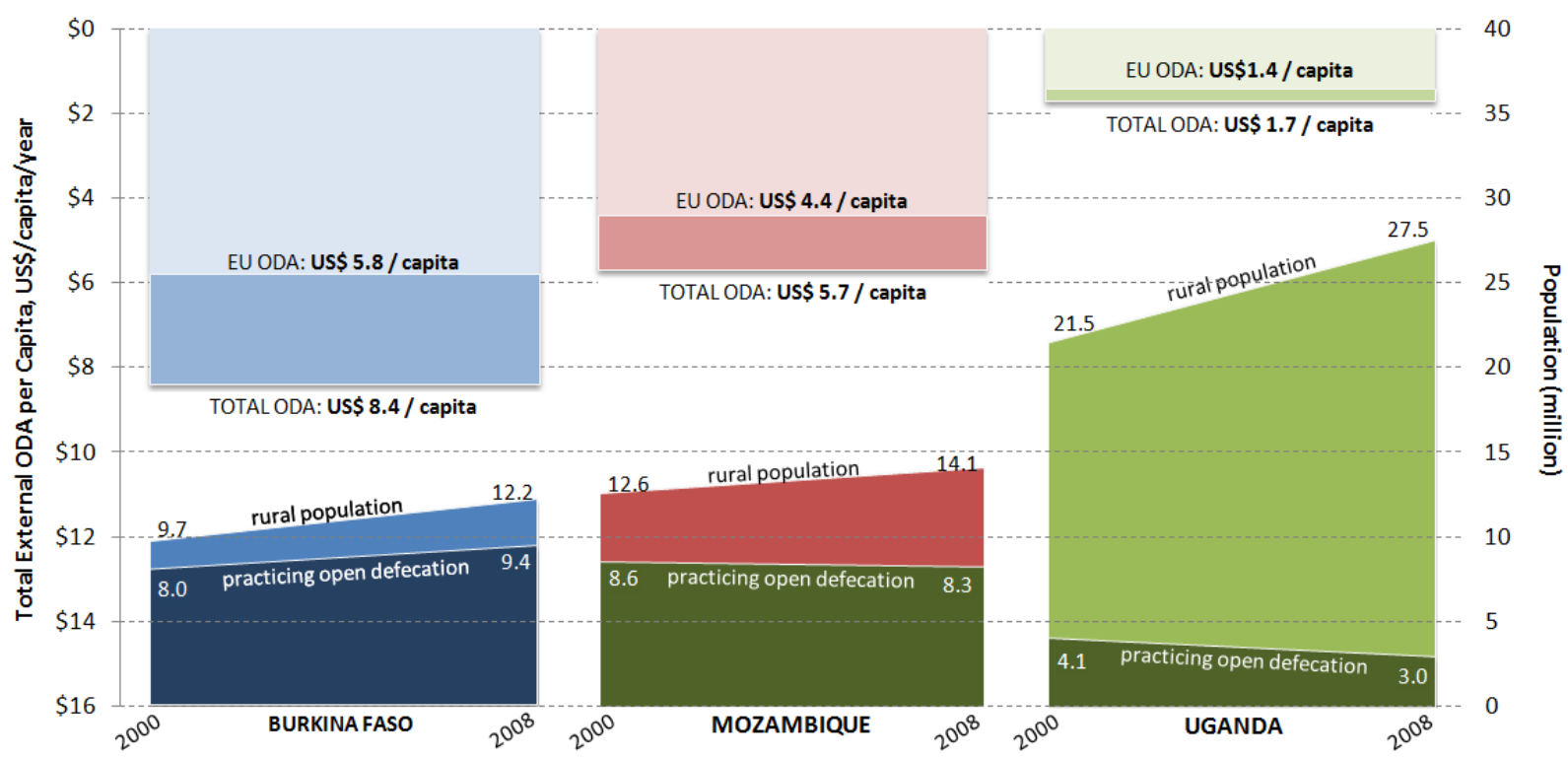

Figure 3. Changes in rural population practising open defecation in relation to ODA

Whilst it is not possible to draw any conclusions from these data concerning cause and effect with respect to rural open defecation trends, subsidy arrangements and the unit capital cost for latrines, the inference is that Uganda has developed relatively cost-effective ways of reducing rural open defecation given that it has zero subsidy and relatively low allocations of ODA per capita. This may of course be showing some effects due to time lag; that is, reform measures may have been put in place in Uganda that have resulted in the relatively positive situation. 
Further analysis attempting to correlate the trends in ODA for basic water supply and sanitation with open defecation was attempted, but the uncertainties in the historic budget allocations are too great to enable meaningful conclusions to be drawn.

\section{Determining the direction of travel}

Whilst the above data do not imply a cause-effect relationship, the findings have potential implications for EU and other donor support; further analysis may help to obtain a sense of 'direction of travel' for countries tackling their sanitation deficit. The situation can be represented in the form of a quadrant plot, Figure 4; this offers a means of locating countries' performance in relation to proxy measures of outcome and input. For example, outcome could be measured by the trajectory in absolute numbers of rural people practising open defecation; input measures could include subsidy levels, per capita latrine costs and per capita ODA allocations.

A country located in the lower left quadrant of the diagram (for example Uganda, with reducing $\mathrm{OD}$, lower subsidy and lower unit costs) has been able to develop a more effective approach than a country located in the upper right quadrant which has low outcome with high input measures (for example Burkina Faso). Therefore, national and donor discussions could focus on ways of moving a particular country out of the top-right hand quadrant, as remaining in this location is clearly not sustainable. Whilst Figure 4 is a snapshot, similar plots could be made over a period of time to track the trajectory of countries' progress. Whilst this is not currently possible due to the lack of longitudinal data for sanitation financing, improvements to national monitoring and continuation of the work of the Country Sector Overviews and GLAAS should enable this to happen in the future. 


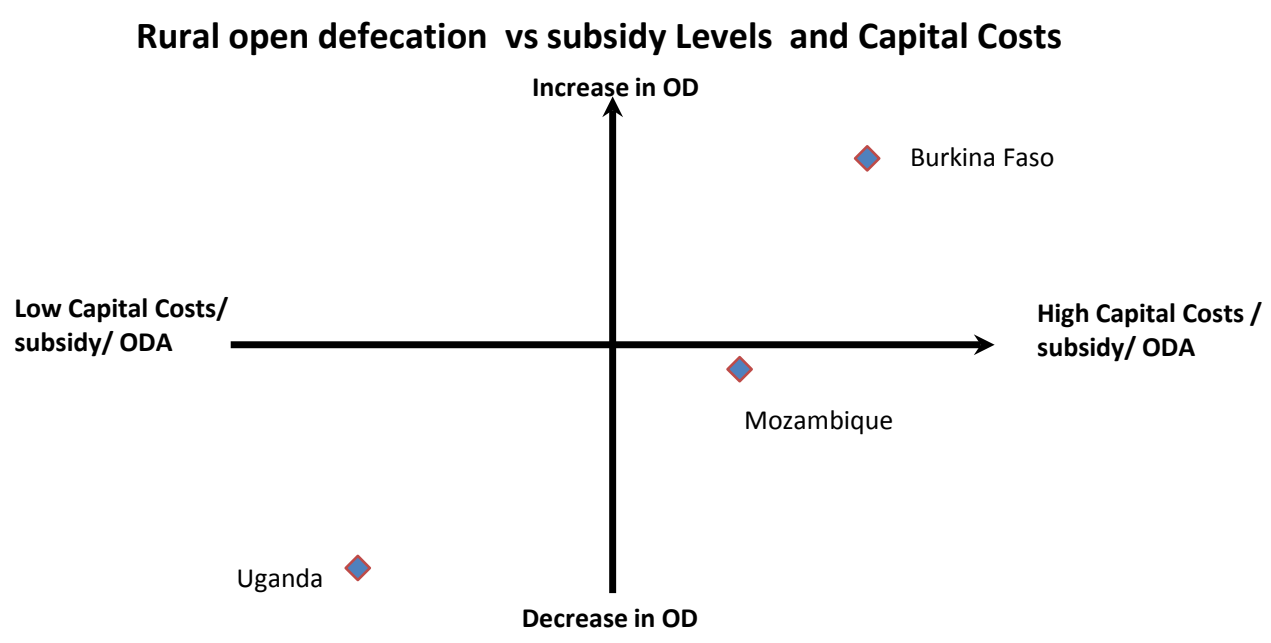

Figure 4. Quadrant diagram for locating relative performance

Similar plots could also be made for other measures, for example relating to per capita ODA allocations and urban outcomes.

GLAAS (2010) reviewed the factors that influence donor aid prioritization, identifying the following as the most important factors: sanitation coverage levels; degree of poverty; established in-country presence of the donor; strong sector plans; and donors’ strategic dialogue with countries. Surprisingly, cost-effectiveness of disbursed funds was not cited; the use of quadrant diagrams could be a useful additional tool to assist donor prioritisation and focus in this respect.

\section{National sector monitoring}

The Country Sector Overview (CSO) reports for Mozambique, Burkina Faso and Uganda all identify problems with monitoring sanitation. There are two main issues. Firstly, those of a generic nature relating to organisational and institutional fragmentation and lack of 
coordination of implementing agencies at the national and sub-national levels, although some improvements are likely to take place, for example through wider public finance reforms in Mozambique. Secondly, a resulting specific problem is that total financial disbursements at country-level for sanitation are largely un-monitorable, as the general practice of both donors and recipients is to report aggregated data for water supply and sanitation. This is amply illustrated by the difficulties encountered in this study regarding the collection of representative data on the disbursement and utilisation of ODA for sanitation. As a consequence, it is not readily possible to directly link disbursements to either outputs or outcomes in sanitation.

The OECD DAC Creditor Reporting System has been modified so that donors can disaggregate reporting of their ODA for sanitation from drinking water supply with effect from 2010 disbursements. However, the nature of the different aid modalities such as programme-based aid means that only a proportion of ODA going to sanitation can actually be identified at the point of outflow of funds from the donors. This places an increasing burden on national governments to develop monitoring and reporting systems that track disbursements in relation to outputs and outcomes. Both internal and external financial flows to sanitation can only realistically be identified at the point of utilisation by radically strengthening national sector monitoring. To be achievable, this will require increasing effort on the part of all donors - it cannot be achieved simply by changes to the reporting structures for OECD DAC, particularly in the light of the fact that the number of individual donor projects and interventions is increasing (Zipper \& Hofbauer 2010). A useful overview of sanitation outcomes is provided by the changes to coverage levels reported via the UNICEFWHO Joint Monitoring Programme. However, this provides too general a picture to make inferences about the effectiveness of ODA and sanitation programmes. Attribution is not 
possible given that disbursements for sanitation cannot yet be tracked; neither is it possible to establish the efficiency or effectiveness of the use of external funds.

This has important implications for both donors and recipients alike in the current environment, where there are strong competing demands for both internal and external funding from different sectors, particularly when viewed in the context of the high levels of support from the EU donors described above. Monitoring is a major concern of the EU donors and has a prominent place in their policies (Box 1). Both the policy framework and the financial imperatives are therefore in place for EU donors to actively support the development of national monitoring systems.

\section{CONCLUSIONS}

European Union donors are a major source of external finance for sanitation in sub-Saharan Africa. Thirty-five percent of the ODA for water supply and sanitation from the eight donors for whom disaggregated data are available goes specifically to sanitation. Fifty-four percent of their ODA for sanitation in sub-Saharan Africa goes to basic sanitation systems. The EU accounts for 59\% of reported ODA for all water supply and sanitation in sub-Saharan Africa and contributes $70 \%$ of the total reported ODA for basic water supply and sanitation, which by inference is targeted towards the poor.

EU donor policies on sanitation are consistent and well-aligned with those of the African Union. Since 2002, both African Countries and European Member States developed either specific sanitation policies or overarching policies that make clear reference to sanitation. There are now consistent policy messages on sanitation that sit within recognized political 
frameworks encompassing both EU Member States and African States; this is a major achievement for Europe and Africa.

In Mozambique, Burkina Faso and Uganda, 86\%-97\% of planned expenditure on sanitation comes from external (donor) sources, with EU donors being the substantive contributors. The EU provides between 53\%-68\% of all ODA for water supply and sanitation across the three countries; for basic water supply and sanitation the EU contributes 70\%-79\% of all ODA. In Mozambique, Burkina Faso and Uganda wide variations exist between rural and urban expenditure allocations with respect to the deficits in sanitation coverage. Contributing issues include the large range of unit costs used to develop expenditure plans and extremely wide variations in subsidy (from zero to 100\%) that do not necessarily align with sanitation outcomes. Only in Uganda have the absolute numbers of rural people practising open defecation fallen substantially between 2000-2008; this is in the context of very low subsidy arrangements and low unit capital cost allocations for latrines. Conversely, Burkina Faso appears to show the opposite trend, with an increase in rural people practising open defecation in the light of high unit capital costs and high subsidies on government-sponsored programmes in 2008.

The use of quadrant diagrams is a potentially useful tool to locate countries' performance in relation to proxy measures of outcome (for example, the absolute number of rural people practising open defecation) and input allocations (for example, per capita latrine costs and per capita ODA) to assist donor prioritisation and focus. Successive plots made over a period of time could be used to track the trajectory of countries' progress and performance in terms of effectiveness and efficiency. 
The current paucity of reliable data for sanitation expenditure (inputs) means that the scope for further in-depth analysis using this approach is limited. However, recent changes to the OECD DAC Creditor Reporting System and the increased scope of future GLAAS reports, in terms of the number of contributing countries, means that significantly more disaggregated data for sanitation will become available, particularly if the AMCOW Country Sector Overview studies are continued. This is particularly significant for developing longitudinal analysis of trends that will greatly assist the understanding of aid effectiveness for sanitation at national level.

There remains a pressing need to improve sanitation monitoring in the three study countries to better understand the links between inputs and outcomes. Financial disbursements to sanitation programmes at country level are largely un-monitorable and it is not possible to link disbursements directly either to outputs or outcomes in sanitation, particularly for rural areas. Financial flows to sanitation can only realistically be identified at the point of utilisation, for example to distinguish between the effectiveness of urban and rural programmes, by radically strengthening national sector monitoring. To be achievable, this will require increasing effort on the part of all donors. Both the policy framework and the financial imperatives are therefore in place for EU donors to actively support the development of national monitoring systems.

\section{ACKNOWLEDGEMENTS}

The authors thank the Africa Working Group of the EU Water Initiative for their financial support and review of this research. 


\section{REFERENCES}

African Sanitation and Hygiene Conference. 2002 Conference Statement on Sanitation and Hygiene in Africa. Johannesburg (Midrand), South Africa. Available at:

http://www.mvula.co.za/images/uploads/Afrisan_Confence_statement.pdf [accessed 11 November 2011].

AMCOW. 2011 Country Status Overviews: Regional Synthesis Report - Pathways to Progress. Water and Sanitation Program-Africa Region, The World Bank, Nairobi, Kenya.

Cotton, A.P., Valfrey-Visser, V., van Maan, P. \& Scott, R.E. 2010 Mapping EU support for sanitation in Africa. Africa Working Group EU Water Initiative, European Commission, Brussels. Available at: http://www.euwi.net/africa/document/highlighted/mapping-eu-support-sanitationafrica-full-report [accessed 11 November 2011].

Ellege, M. F., Rosenweig, F. \& Warner, D. B. 2002 Guidelines for the assessment of national sanitation policies. EHP Strategic Report No 2, CDM and Associates, Arlington, VA, USA.

eThekwini Declaration and AfricaSan Action Plan. 2008 Meeting the Millennium Development Goals on Water and Sanitation. 11th African Union Summit, eThekwini, South Africa. Available at: http://www.africasan3.com/Images/eThekwiniAfricaSan.pdf [accessed 18 October 2010].

EU Water Initiative Africa Working Group. 2008a Africa-EU Statement on Sanitation. Available at: http://www.euwi.net/multi-stakeholder-forum/document/euwi/africa-eustatement-sanitation [accessed 11 November 2011].

EU Water Initiative Africa Working Group. 2008b Working Together to Improve Aid Effectiveness in the Water Sector. European Commission, Brussels.

GLAAS. 2010 UN-Water Global Annual Assessment of Sanitation and Drinking-Water. WHO, Geneva, Switzerland.

Klutsé, A., Bouraima, Z. \& Amegnran, C. 2010 Sanitation costs analysis in Burkina Faso. Pumps, Pipes and Promises, IRC Symposium, The Hague, Netherlands, 16-18 November 2010.

OECD Development Co-operation Directorate. 2010 The List of CRS Purpose Codes taking effect in 2011 reporting on 2010 flows. Available at: http://www.oecd.org/document/21/0,3746,en_2649_34447_1914325_1_1_1_1,00.htm 1 [accessed 18 November 2011].

OECD Development Co-operation Directorate (n.d.) StatExtracts Creditor Reporting System. Available at: http://stats.oecd.org/Index.aspx?DatasetCode=CRSNEW [accessed 8 October 2010].

WEDC. 2005 Assessing National Sanitation Policy: A series of WEDC Briefing Notes. WEDC, Loughborough University, UK.

WELL. 2005a Will it cost the earth? An overview of cost estimates for achieving the water and sanitation targets of the Millennium Development Goals. WELL Briefing Note 9. WEDC, Loughborough University, UK.

WELL. 2005b Allocating national resources in the water and sanitation sector. WELL Briefing Note 11. WEDC, Loughborough University, UK 
WHO/UNICEF. 2010 Progress on sanitation and drinking water: 2010 update. WHO/UNICEF Joint Monitoring Programme for Water Supply and Sanitation, WHO, Geneva, Switzerland.

Zipper, T. \& Hofbauer, S. 2010 EU donors and Aid effectiveness in the WASH Sector. EU Water Initiative Africa Working Group, European Commission, Brussels. Available at:

http://www.euwi.net/files/EU_donors_and_Aid_effectiveness_in_the_WASH_sector. pdf [accessed 11 November 2011]. 